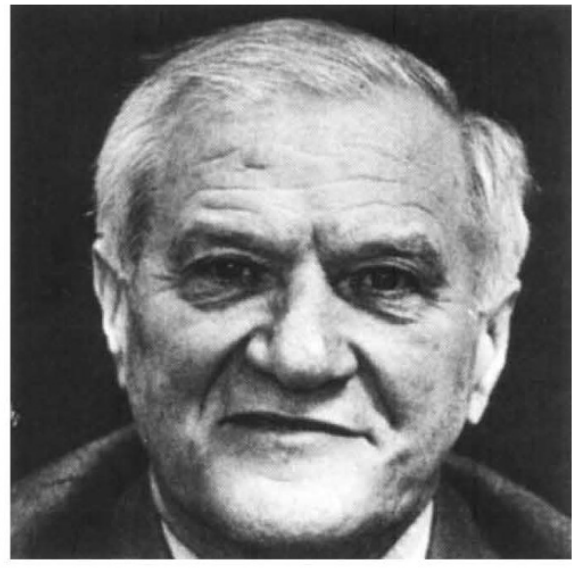

Common sense, perseverance and ingenuity

\section{John Ziman}

IN the short run, the developing countries are seeking scientific and technological information; in the long run, to make use of that information and to serve their own needs, they will need research capability.

- In the short run, that means material facilities; in the long run, these are merely the instruments of scientific institutions.

-In the short run, a scientific institution is

Dedijer: information revolution

A basic capacity to absorb and create knowledge

\section{Hiroshi Harada}

THERE is much that can be said on the topic of 'Science and Technology for Development', but as far as developing countries are concerned it is useless unless they have in the first place a basic capacity to absorb and create scientific and technological knowledge, and to be adept in its use for productive and commercial purposes. This obvious fact seems, nevertheless, to be often overlooked, as is the fact that there is no short cut to acquiring it.

Education is the only universal means for forming this capacity from the innate intelligence available. And in this context, education must not be regarded solely as a process of passing on information and experience, but one which stimulates the curiosity of its recipient and develops a sense of applicability of the knowledge acquired. It must increase practical ability and the powers of observation and communication. It must instil mental selfdiscipline and ruthlessly maintain standards and integrity in study and research. These - and a willingness to be self-critical - are essential for selfreliance, both individually and nationally.

The process must be started deliberately at the primary level of education. It is too late at the secondary and higher levels, when the sheer weight of knowledge to be acquired can inhibit any burgeoning sense of mastery over it. This applies whether the product of the educational system is a professional scientist or technologist, or a layman. Indeed, an appreciation by the latter of what is involved is essential if the impact of science is to be accepted and the technological revolution necessary for development is to take place. Otherwise, scientists and technologists become, as is seen too frequently in developing countries, elitist and largely ineffectual in the development process.

Prof Harada is a Japanese plant physiologist, currently with UNESCO a bureaucratic organisation; in the long run it must grow into a scientific community. In the short run, a scientific community is made up of technically qualified personnel; in the long run, it depends on the leadership of its scientists.

-In the short run, a scientist is an expert who has passed the examinations for a $\mathrm{PhD}$; in the long run, this is only an apprenticeship to the profession of research.

-In the short run, the goal of research is to make specific contributions to knowledge; in the long run, it is to exercise curiosity and to solve problems.

- In the short run, problems are often specialised expertise; in the long run this calls for common sense, perseverance, and open mind and ingenuity.

A scientific institution with some capability for research can be set up in about 5 years. Scientific workers with some research experience can be trained in about 10 years. It takes a generation or so of education and cultural change to foster the personal qualities needed to solve practical problems by scientific methods. This path is long and narrow, but it is the only known way. For the developing countries there is no time to lose: they, and we, must start now.

Prof Ziman is head of the Department of Physics, University of Bristol

\section{Breaking the monopoly on scientific knowhow}

\section{S. Dedijer}

I SEE three threats in UNCSTD to developing countries developing their own capability to find out, to discover, to invent and to innovate in both predictable and unforeseen circumstances. Two of them are strongly backed proposals for deceptive solutions to the problems which arise from the fact that almost all the global scientific and technological output, capability and knowhow is concentrated in only 30 countries, from which the solved by the application of sophisticated, remaining $80 \%$ of the world has to import.

The first threat would arise if UNCSTD set up one more UN organisation to 'deal' with the problem, without a critical evaluation of the efficacy of the existing ones. The second threat could come from the search for solutions to the problem in political attacks against 'capitalist dependence' of the developing countries without the realisation that such non-'dependent' countries as the USSR and China are almost colonially dependent on the science and technology of the democratic countries.

The most serious threat is that the developing countries, as shown by their UNCSTD national papers, have done their homework badly. Not one of them seems to have yet discovered the very fact of the new electronic information revolution, or has realised its implications for development. This includes the fact that information democracy - the right and motivation of everyone in a country to obtain, produce, distribute and withold information - is becoming essential for a country's ability to acquire and create scientific and other knowledge and knowhow. Democracy, in other words, is becoming a productive force.

UNCSTD itself offers the delegation from every developing country the opportunity to test critically the approach, the findings and recommendations in their national papers and to apply them creatively for national goals after UNCSTD.

Prof Dedijer is at the Research Policy Institute, University of Lund

\section{Active partnership of Third World \\ scientists}

\section{Yongyuth Yuthavong}

THE challenge of science and technology today is not to show that it can give rise to social benefits, but that these benefits are produced where they are most wanted - in the Third World. There is an urgent need to direct a far larger part of world scientific and technological activities specifically towards Third World development. Solutions to many development problems have to be sought largely within the developing countries themselves, and their scientists and technologists must be given the necessary means to search for them. Solutions to many problems, for example in the fields of population, nutrition and health, are already known but lack implementation. An integrated approach including all necessary social, economic and political components is needed.

The developed countries have the capacity to find scientific solutions to many basic problems concerning the survival of mankind, and should make more effort in this direction. However, ultimately, effective action in the Third World 
depends on the competence and morale of its own scientists, technologists and other colleagues, and sufficient appreciation by its general public of the value of scientific solutions to development.

Support from developed countries could take the form not only of direct financial assistance, but of collaboration between individuals and agencies concerned with issues ranging from basic research to industrial consultation, and the dissemination of packaged technology to an illiterate rural population. In short, an active partnership of Third World scientists and technologists is an important prerequisite for success of development efforts. It is, furthermore, important to make the general public in the Third World - especially the few leaders with so much influence - aware of the critical role of science and technology in development, and to make the necessary tools available. $\mathrm{Dr}$ Yuthavong is at Mahidol University, Bangkok

\section{Three imperatives: food storage, energy, work ... Guido Brunner}

A GREAT responsibility rests on those who will be taking part in UNCSTD in Vienna. They have to make a fundamental choice. They will either be drawn into a discussion of abstract principles of a new international economic order, or - and this is what I hope to see $\rightarrow$ they will get down to some practical business. The first will merely lead to yet another diplomatic deadlock of the kind we have seen already too often in meetings between the developed and developing world. The other will spark off that real scientific and technical co-operation which is so necessary for the solution of the problems of development.

This is an especially significant time for the conference. Prospects for the world economy are clouded, and governments are worried about the rising cost, and shortages, of energy. For the developing

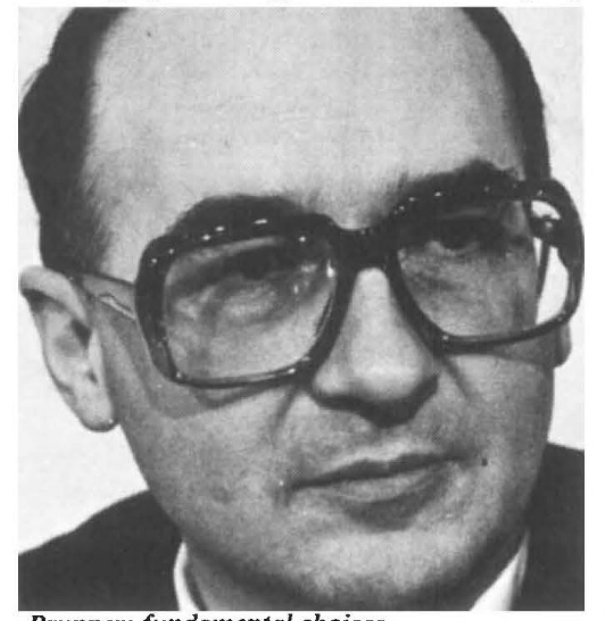

Brunner: fundamental choices world the three imperatives are: the storage of food, energy and work. The conference must see that the proper scientific and technological resources are freed to contribute to these great tasks.

A long term effort internationally and at home will be required if the developing countries are to build up the necessary internal scientific and technological capability. The transfer of technologies from the developed to the underdeveloped is only one aspect of the problem. What is equally important is to establish the means for the developing countries to improve their educational and managerial standards.

The Community and its nine Member States will play their part in this great venture. Our association with 57 developing countries in Africa, Asia and the Caribbean within the Lomé Convention has already enabled us to make a contribution, and the new Lomé Convention will provide us with a framework for offering additional support for scientific and technical co-operation.

Dr Brunner is Commissioner of the European Communities for Energy, Research, Science, and Education

\section{Policymaking should be at the highest level of authority}

\section{Antonio Pinilla}

THE most pressing need is for a strong, deep and consistent political decision that science and technology constitute essential elements for each state to obtain:

\section{- social integration;}

-economic development;

\section{- cultural independence;}

opolitical coherence; and

- administrative efficiency and productivity.

Inadequate knowledge generates racial, social or religious prejudice, frustrating the national integration of countries. Economic growth requires agricultural and industrial mechanisation and rationalisation and these are impossible without a certain advanced degree of scientific and technological development. Payment of duties and royalties make national products uncompetitive in international markets. Economic dependence often generates cultural dependance, so decreasing awareness of national identity. Political and administrative sciences are key solutions to problems concerning political coherence, continuity, administrative efficiency and productivity within a free society.

For these reasons the making of science and technology policy should be the responsibility of the highest levels of authority, such as the president of the Republic (Head of State), parliament and

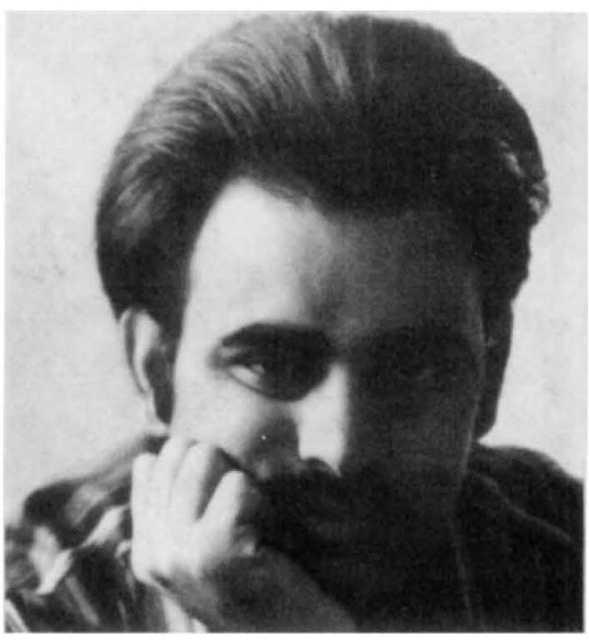

Sardar: self-confidence

the cabinet. The person in charge of implementing science and technology policy should have the rank of minister of state, or even better, be a full cabinet member.

The usual type of problem confronting each cabinet member is something very specific and urgent. Cabinet members cannot afford to concentrate on the scientific and technological aspects of the problems they face. That is why it is critically important that present-day states create national systems of science and technology, giving them the highest level of responsibility and authority to ensure scientific and technological aspects of national plans and objectives, policies and actions are sound, do not include errors or insufficient information, and are adequate and appropriate to each national reality.

Prof Antonio Pinilla is President of the Peruvian Consejo Nacional de Investigacion Cientifica, Lima

\section{Inculcating an}

\section{appropriate sense of confidence}

\section{Ziauddin Sardar}

ALL developing starts with the individual, and science development is no exception. The first and the most critical action, in my book, concerns the scientists of the developing countries themselves: every Third World scientist must consciously inculate in him/herself an appropriate sense of confidence. Science can only play its full role in development when the integrity of those who do science is preserved. And this integrity cannot be preserved when the Third World scientists themselves do not have any confidence in their ability to manage their enterprise.

There is a natural corollary to the development of confidence in Third World scientists: confidence in oneself procedes from confidence in one's society, tradition, culture and institution. If someone has confidence in his ability as a scientist and 